\title{
Potential Pricing Discrimination Due to Inaccessible Web Sites
}

\author{
Jonathan Lazar ${ }^{1}$, Brian Wentz ${ }^{2}$, Matthew Bogdan ${ }^{1}$, Edrick Clowney ${ }^{1}$, \\ Matthew Davis ${ }^{1}$, Joseph Guiffo ${ }^{1}$, Danial Gunnarsson ${ }^{1}$, Dustin Hanks ${ }^{1}$, \\ John Harris ${ }^{1}$, Behnjay Holt ${ }^{1}$, Mark Kitchin ${ }^{1}$, Mark Motayne ${ }^{1}$, \\ Roslin Nzokou $^{1}$, Leela Sedaghat ${ }^{1}$, and Kathryn Stern ${ }^{1}$ \\ ${ }^{1}$ Towson University, Department of Computer and Information Sciences, \\ Towson, MD, USA 21252 \\ jlazar@towson. edu \\ ${ }^{2}$ Frostburg State University, Department of Computer Science and \\ Information Technology, Frostburg, MD, USA 21532 \\ bwentz@acm.org
}

\begin{abstract}
Although tools and design guidelines exist to make web sites accessible, a majority of web sites continue to be inaccessible. When a web site offers special prices that are available only on the web site (not the physical store), and the web site itself is inaccessible, this can lead to discriminatory pricing, where people with disabilities could end up paying higher prices than people without disabilities who can access the web site and take advantage of the online-only prices. This research examined whether 10 of the top ecommerce web sites which offer online-only price specials are accessible. The results revealed that there were multiple categories of accessibility violations found on all of the evaluated web sites.
\end{abstract}

Keywords: discrimination, web accessibility, disabilities, e-commerce.

\section{Introduction}

Web accessibility is the concept of making sure that web sites can work properly for users with disabilities that are using alternative input or output devices, such as screen readers or adaptive keyboards. Typically, for a web site to be accessible, it must follow a set of design guidelines, such as the web guidelines from Section 508 (U.S. Law), or the Web Content Accessibility Guidelines (WCAG) from the Web Accessibility Initiative (WAI). Other countries also have legislation that relates to web site accessibility, including the Equality Act in the U.K. [6], Act on Equal Opportunities for Disabled Persons in Germany [4], and the Disability Discrimination Act in Australia [1], to name a few.

Although tools and design guidelines exist to make web sites accessible, a majority of web sites continue to be inaccessible. Various authors have documented how U.S. federal and state government web sites, university web sites, airline web sites, e-commerce sites, and employment web sites continue to be inaccessible 
[5],[7],[8],[8],[10]. However, there is an additional problem: web site inaccessibility often leads to other unwanted societal effects, such as pricing discrimination. A previous study documented that, when airline web sites are inaccessible, people with disabilities must use the airline call center, which can lead to the individual paying a higher airfare (even though that is against the law) [11].

For many stores, there are two components to the enterprise: the physical, brick and mortar store, and the online, e-commerce site. These two components are often tightly integrated (for instance, stores such as Wal-Mart allow a customer to order from the web site and have an item shipped to a local store), but many e-commerce sites offer special web-only prices which are not available in the physical store or over the phone. When a web site offers special prices that are available only on the web site, and the web site itself is inaccessible, this can lead to discriminatory pricing.

\section{Research Methodology}

There were two components to this research: stage one was determining which large stores have both physical and online components and offer special web-only prices, and stage two was evaluating those web sites for accessibility. The 50 largest ecommerce sites in the U.S. according to [2] were narrowed to 41 sites which had both physical stores and e-commerce sites (the other nine e-commerce sites, such as Amazon.com and Zappo's, had no physical counterpart). Next, those 41 web sites were examined to determine which sites had web-only special prices using the following five-step process:

1. Examined a few items, to see if there was a separate online-only price.

2. Searched for a "hot deals" (or something similar) section on the web site, and checked for online-only deals. Checked if there are any flyers or deals located only in a local area (if a zip code is required).

3. Searched the e-commerce site's search engine using the phrase "online only."

4. Searched using Google advanced search, set to the domain of the e-commerce site, and the exact phrase "online only" (because many web site search engines are actually product search engines, not keyword search engines).

5. Signed up for an email mailing list for specials, and monitored for a week to determine if any web-only specials were sent out.

After evaluating for online-only prices or specials, it was determined that the 10 largest stores that had online-only prices (in order, starting from the largest) were: Staples, Office Depot, OfficeMax, Sears, BestBuy, Costco, Victoria's Secret, Macy's, Gap Direct, and Neiman-Marcus. To evaluate the accessibility of the web sites during stage two, expert inspections were conducted (with multiple, independent evaluators for each web site) using a screen reader, since this is considered to be the most effective form of accessibility evaluation for compliance with standards [12] and most accurate when multiple evaluators inspect the same web site [10].

The expert evaluations were conducted during November and December 2010 by utilizing the web site accessibility standards of Section 508 (1194.22) of the U.S. Rehabilitation Act, which involve 16 guidelines, which are referred to as paragraphs 
"a" through "p" [14]. The expert evaluation process was guided by the "Absolute Minimum Accessibility Inspection" which has been used effectively in other accessibility evaluations [10]. Each "paragraph" of the Section 508 guidelines is considered to be weighted equally, and the existence of a paragraph violation for a web site was recorded. Each web site was individually evaluated by a minimum of four individuals without disabilities (due to the total number of evaluators involved, some web sites received five evaluations). All evaluators then met, discussed their individual evaluations, and compiled one meta evaluation, which typically has a higher level of validity than only one evaluation [13]. Table 1 is a summary of the Section 508 guidelines with the associated "paragraph" letters.

Table 1. Summary description of the 16 paragraphs of the U.S. Section 508 web guidelines

\begin{tabular}{ll}
\hline Paragraph & Summary Description \\
\hline A & Text Equivalent (have a text equivalent for any graphical elements) \\
B & $\begin{array}{l}\text { Synchronized Equivalent Alternatives (have captioned video, transcripts of } \\
\text { any audio, or other alternatives for multimedia) }\end{array}$ \\
C & $\begin{array}{l}\text { Use of Color (color should not be used as the only method for identifying } \\
\text { elements of the web page or any data) }\end{array}$ \\
Organization (style sheets are encouraged, but users should still be able to \\
utilize a web page when style sheets are turned off) \\
E, F & $\begin{array}{l}\text { Redundant Text Links on Server-Side Image Map and (f) Client-Side Image } \\
\text { Maps (redundant clickable links for server-side image maps, and accessible }\end{array}$ \\
client-side image maps are preferred) \\
Row and Column Headers (use appropriate headers and markup to allow easy \\
navigation of a table)
\end{tabular}

\section{Results}

The accessibility evaluations of these web sites revealed that all 10 web sites violated at least one paragraph of the Section 508 guidelines, with an average of three 
paragraphs violated per web site. The variety of violations ranged from OfficeMax violating only paragraph a (alternate text equivalent) to Costco violating five paragraphs (a, d, h, i, and o). Staples violated paragraphs a, b, and $\mathrm{m}$ with buttons and images that did not have alternate text and flash content without an alternative. An example of the impact this could have on pricing was that the Staples "Cyber Monday" links were not accessible. OfficeDepot also violated the same three paragraphs for similar reasons, and a promotional video lacked transcripts or captioning. Office Max violated only paragraph a (lack of text equivalent for some of the graphical elements on the site). Sears violated paragraphs $a, b$, and o with lack of alternate text, no method of skipping repetitive navigational links and the lack of transcripts or captioning for a promotional deals video.

BestBuy violated paragraphs $a, b, f$, and $m$ with the lack of alternate text, a flash video with no alternative way to reach or read the content, and no links to the required plug-in. An example of the impact that this could have on pricing discrimination is the "deals" section that cannot be accessed without the use of a mouse on the BestBuy web site as illustrated in Figure 1.

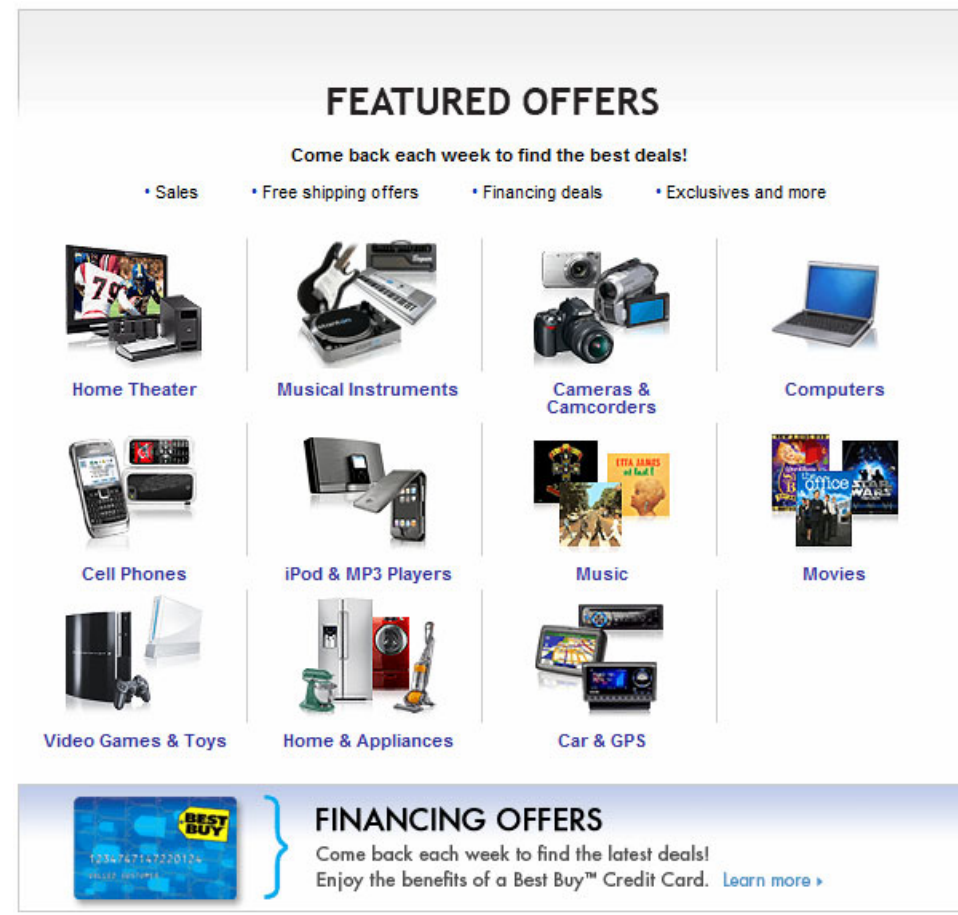

Fig. 1. Screenshot of the deals section on the BestBuy web site which cannot be accessed by the keyboard alone

Costco had violations in five paragraphs (a, $\mathrm{d}, \mathrm{h}, \mathrm{i}$, and o), and those violations included the lack of functional skip navigation links, poor alternate text, lack of functionality without the style sheet, and frames and tables that were not labeled or poorly 
labeled. Victoria's Secret violated paragraphs a and o, with lacking alternate text and a method to skip repetitive navigational links. The Macy's web site violated paragraphs $\mathrm{a}, \mathrm{b}$, and 1 with lack of alternate text, inaccessible videos, and a script to display a promotional code that was not accessible with a screen reader. GapDirect violated paragraphs a, $1, \mathrm{~m}$, and $\mathrm{n}$ with lack of alternate text, inaccessible scripting, no link for the flash plug-in, and unlabeled form fields. Neiman-Marcus violated paragraphs a, n, and o with lack of alternate text on images and buttons, forms with incorrect labels, and no link to skip repetitive navigational links. Table 2 shows the results of which web sites violated which paragraphs of the Section 508 guidelines.

Table 2. Results of Violations of the Section 508 Guidelines

\begin{tabular}{|c|c|c|c|c|c|c|c|c|c|c|}
\hline 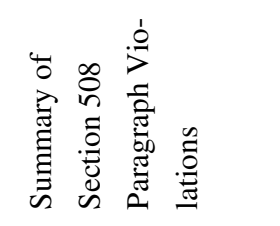 & $\frac{\frac{\omega}{0}}{\frac{\pi}{2}}$ & 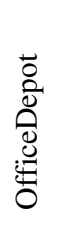 & 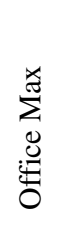 & 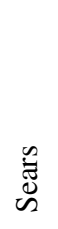 & 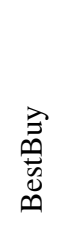 & ن⿺辶 & 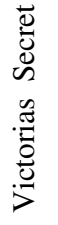 & $\begin{array}{l}\infty \\
\stackrel{0}{\tilde{m}} \\
\sum\end{array}$ & 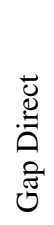 & 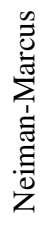 \\
\hline $\begin{array}{l}\text { a) Alternate text for } \\
\text { images/other visuals }\end{array}$ & $\mathrm{x}$ & $\mathrm{x}$ & $\mathrm{x}$ & $\mathrm{x}$ & $\mathrm{x}$ & $\mathrm{x}$ & $\mathrm{x}$ & $\mathrm{x}$ & $\mathrm{x}$ & $\mathrm{x}$ \\
\hline $\begin{array}{l}\text { b) Synch. Multime- } \\
\text { dia }\end{array}$ & $\mathrm{x}$ & $\mathrm{x}$ & & $\mathrm{x}$ & $\mathrm{x}$ & & & $\mathrm{x}$ & & \\
\hline $\begin{array}{l}\text { c) Meaning through } \\
\text { color also avail. w/o }\end{array}$ & & & & & & & & & & \\
\hline $\begin{array}{l}\text { d) Readable w/o } \\
\text { CSS }\end{array}$ & & & & & & $\mathrm{x}$ & & & & \\
\hline $\begin{array}{l}\text { e,f) Server/Client- } \\
\text { side image maps }\end{array}$ & & & & & $\mathrm{x}$ & & & & & \\
\hline $\begin{array}{l}\text { g,h) Table headers/ } \\
\text { markup }\end{array}$ & & & & & & $\mathrm{x}$ & & & & \\
\hline $\begin{array}{l}\text { i) Frames have } \\
\text { labels }\end{array}$ & & & & & & $\mathrm{x}$ & & & & \\
\hline $\begin{array}{l}\text { j) No blinking or } \\
\text { flashing }\end{array}$ & & & & & & & & & & \\
\hline $\begin{array}{l}\text { k) Text page if } \\
\text { needed }\end{array}$ & & & & & & & & & & \\
\hline $\begin{array}{l}\text { 1) Scripting lan- } \\
\text { guages }\end{array}$ & & & & & & & & $\mathrm{x}$ & $\mathrm{x}$ & \\
\hline m) Applets/Plug-ins & $\mathrm{x}$ & $\mathrm{x}$ & & & $\mathrm{x}$ & & & & $\mathrm{x}$ & \\
\hline n) Forms & & & & & & & & & $\mathrm{x}$ & $\mathrm{x}$ \\
\hline o) Skip navigation & & & & $\mathrm{x}$ & & $\mathrm{x}$ & $\mathrm{x}$ & & & $\mathrm{x}$ \\
\hline p) Timed response & & & & & & & & & & \\
\hline $\begin{array}{l}\text { Total Categories } \\
\text { Violated }\end{array}$ & 3 & 3 & 1 & 3 & 4 & 5 & 2 & 3 & 4 & 3 \\
\hline
\end{tabular}




\section{Conclusion}

Companies must pay careful attention to the accessibility of their interfaces, particularly so that all individuals are provided equal access to all content. If people with disabilities cannot access pricing "deals" or "specials" on e-commerce web sites, it could lead to pricing discrimination. Discrimination against an individual on the basis of disability is clearly against the law in many countries. In the U.S., the 2007 court case involving Target.com [3] illustrated the necessity for businesses to pay closer attention to web site accessibility.

Individuals involved in designing or maintaining these interfaces must carefully design to standards, such as WCAG. WCAG (Web Content Accessibility Guidelines) form the basis for web accessibility policies throughout the world, including Section 508 in the U.S. One example of how the accessibility violations discovered in this study conflict with WCAG is seen in WCAG 2.0 Principle 2, which specifies that interfaces must be navigable through a keyboard interface [15].

Some basic recommendations that can significantly improve the accessibility of a web site can be derived from either WCAG or other regulations, such as Section 508 in the U.S. (recall Table 1). WCAG 2.0 summarizes its guidelines by an interface being perceivable, operable, understandable, and robust [15]. Perceivable means that an interface must provide alternatives for the types of media that are presented, whether inherently visual, auditory, or haptic. Operable means that all users can read and use the content, even from a keyboard alone. It also means that users should have enough time to read content, be easily able to know where they are, and be confident that the design of an interface will not inherently cause a seizure. Understandable means that content should be readable and easy to understand, have predictable operation, and assist users with avoiding and correcting mistakes. Robust means that an interface should be able to be accessed regardless of the technology used to access it, including assistive technologies [15].

Policymakers and those responsible for enforcing current laws (including civil rights legislation) should be aware of the impact that web inaccessibility can have on the civil rights of individuals with disabilities. Following guidelines such as WCAG and performing regular evaluations on the accessibility and usability of an interface, involving users with disabilities, accessibility experts, and automated evaluation tools will help to prevent possible discrimination problems, such as the ones discussed in this study. More research needs to be done on how inaccessible web sites can lead to unwanted and possibly illegal actions such as pricing discrimination, employment discrimination, and societal exclusion.

\section{References}

1. Australian Human Rights Commission: Disability Rights, http://www.hreoc.gov.au/disability_rights /

2. Davis, D. (ed.): Internet Retailer: 2009 Top 500 Guide, Vertical Web Media, Chicago (2009)

3. Frank, J.: Web Accessibility for the Blind: Corporate Social Responsibility or Litigation Avoidance? In: 41st Hawaii International Conference on System Sciences, pp. 1-8 (2008)

4. Federal Ministry on Labor and Social Affairs: Disability Policy, 
http: //www.bmas.de/portal/45136/disability_policy.html

5. Gladstone, K., Rundle, C., Alexander, T.: Accessibility and Usability of eCommerce Systems. In: Miesenberger, K., Klaus, J., Zagler, W.L. (eds.) ICCHP 2002. LNCS, vol. 2398, pp. 11-18. Springer, Heidelberg (2002)

6. Government Equalities Office: Equality Act 2010, http://www.equalities.gov.uk/equality_bill.asp

7. Hull, L.: Accessibility: it's not just for disabilities any more. Interactions 11(2), 36-41 (2004)

8. Jaeger, P.T.: Assessing Section 508 compliance on federal e-government Web sites: A multi-method, user-centered evaluation of accessibility for persons with disabilities. Government Information Quarterly 23(2), 169-190 (2006)

9. Kane, S., Shulman, J., Shockley, T., Ladner, R.: A web accessibility report card for top international university web sites. In: 2007 International Cross-Disciplinary Conference on Web Accessibility (W4A), pp. 148-156. ACM, New York (2007)

10. Lazar, J., Beavan, P., Brown, J., Coffey, D., Nolf, B., Poole, R., Turk, R., Waith, V., Wall, T., Weber, K., Wenger, B.: Investigating the Accessibility of State Government Web Sites in Maryland. In: Langdon, P., Clarkson, P., Robinson, P. (eds.) Designing Inclusive Interactions, pp. 69-78. Springer, London (2010)

11. Lazar, J., Jaeger, P.T., Adams, A., Angelozzi, A., Manohar, J., Marciniak, J., Murphy, J., Norasteh, P., Olsen, C., Poneres, E., Scott, T., Vaidya, N., Walsh, J.: Up in the Air: Are Airlines Following the New DOT Rules on Equal Pricing for People with Disabilities When Websites are Inaccessible? Government Information Quarterly 27(4), 329-336 (2010)

12. Mankoff, J. Fait, H., Tran, T.: Is your web page accessible?: a comparative study of methods for assessing web page accessibility for the blind. In: SIGCHI Conference on Human Factors in Computing Systems, pp. 41-50 (2005)

13. Nielson, J., Mack, R. (eds.): Usability Inspection Methods. John Wiley and Sons, New York (1994)

14. U.S. Government: Section 508, http: / / www . section 508 .gov

15. WC3. Web Content Accessibility Guidelines (WCAG) 2.0 (2008), http: / /www.w3 . org/TR/WCAG/ 